\title{
Mixed Ligand Complexes of Alkali Metal Salts of Some Organic Acids with O-Hydroxyacetophenone Phenylhydrazone -2, 4 - Dinitrophenyl Hydrazone
}

\author{
Shahnawaz Mahmood \\ Associate Professor and Head of the Department of Applied Sciences \& Humanities, Mewat Engineering College \\ Palla, Nuh, Haryana - 122107
}

\begin{abstract}
In continuation to our project for exploring the mechanism of selective absorption of alkali metals by plants as well as the possible role of alkali metals cations in plant metabolism Chemistry of alkali metals would facilitate fuller understanding of the mechanism. The study of the Coordinator Chemistry of these metals has been undertaken.Our aim has been to synthesize new alkali metals complexes and to identify the various structural features in the ligands, which enhance their selectivity for complex formation with alkali metals icons.
\end{abstract}

Keywords: O-hydroxyacetophenone phenylhydrazone, -hydroxyacetophenone - 2,4 - dinitrophenyl hydrazone salicylaldehyde, anthranilic acid, Picolinic acid and Quinaldinic acid

\section{Introduction}

In previous chapters, we have described the preparation of a large number of mixed ligand alkali complexes involving potential chelating ligand, having oxygen and nitrogen as the donor atoms.

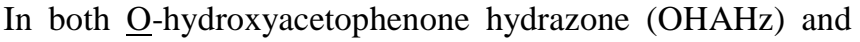
O-hydroxyacetophenone phenylhydrazone (OHAPHz), the donors are the nitrogen atoms of the hydrazone moiety and the oxygen atom of $-\mathrm{OH}$ moiety. Both the types of hydrazones formed mixed ligand complexes of the type ML.HL', where $\mathrm{M}=\mathrm{Li}$, Na or $\mathrm{K} ; \mathrm{L}=$ deprotonated organic acid and $\mathrm{HL}^{\prime}=\underline{\mathrm{O}}$-hydroxyacetophenone hydrazone or $\underline{\mathrm{O}}-$ hydroxyacetophenone phenylhydrazone.

It has been observed that the chelating ability of $\underline{\mathrm{O}}-$ hydroxyacetophenone hydrazone is greater than that of $\underline{\underline{O}}-$ hydroxyacetophenone phenylhydrazone, suggesting thereby that substituted hydrazones become more selective in their behaviour towards alkali metal cations. We now extend our investigation to study the possible complex formation by alkali metals with the ligand $\underline{\mathrm{O}}$-hydroxyacetophenone $-2,4$ - dinitrophenyl hydrazone, hereafter abbreviated as OHA 2, $4-\mathrm{DNPz}$

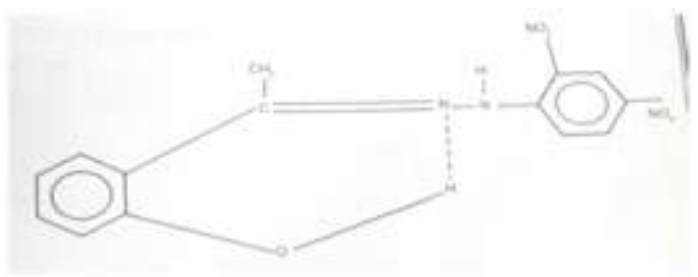

Figure 6.1

Our usual method of preparing these complexes was to take equimolar proportion of the alkali metal salt (ML) and the title ligand $\underline{O}$-hydroxyacetophenone - 2, 4 - dinitrophenyl hydrazone (HL') in absolute ethanol in a conical flask and to reflux the contents for four to six hours with continuous stirring. A clear solution was obtained. It was concentrated and cooled, when adduct came apart. It was filtered, washed with absolute ethanol and then dried in an electric oven at $80^{\circ} \mathrm{c}$. Adducts did not separated in case of potassium oxinate and potassium 1 - nitroso -2 - naptholate.

Table 6.1 lists the mixed ligand complexes of $\underline{\mathrm{O}}$ hydroxyacetophenone - 2, 4 - dinitrophenyl hydrazone which we have obtained.

Table 6.1: Mixed Ligand Complexes of OHydroxyacetophenone - 2, 4 - dinitrophenylhydrazone

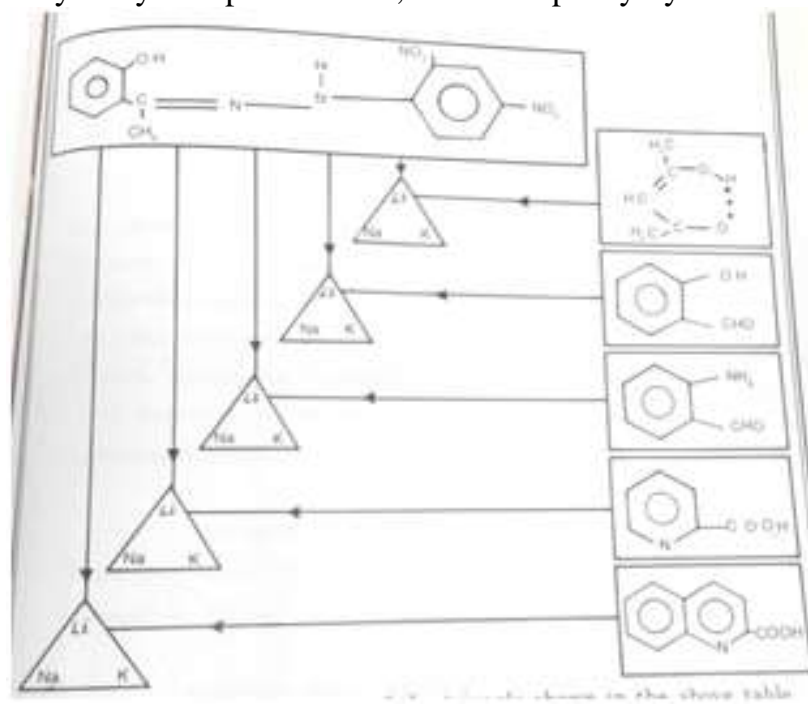

The three corners of the triangle shown in the above table represent the alkali metals $\mathrm{Li}, \mathrm{Na}$ and $\mathrm{K}$. Where the symbol appears, the complex ML.HL'. Could be obtained. Crosses indicate that the corresponding complexes could not be obtained.

\section{Physical Properties}

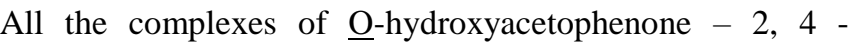
dinitrophenyl hydrazone with alkali metal salts are characteristically coloured. They are stable in air under dry conditions for reasonable long periods of time. They are stored in corked sample tubes over anhydrous calcium

\section{Volume 6 Issue 12, December 2017}




\section{International Journal of Science and Research (IJSR) \\ ISSN (Online): 2319-7064 \\ Index Copernicus Value (2016): 79.57 | Impact Factor (2015): 6.391}

chloride in a desicator. They are hygroscopic in nature. They are soluble in most polar solvents, but are insoluble in nonpolar solvents. The additional ligand molecule is not removed by benzene or ether. However, studies in solution and measurements of the common solvents in which they dissolve. Also the solvents used, e.g. ethanol, acetone and $\mathrm{N}$ - methyl - 2 - pyrrolidone can not be regarded as inert, since they may coordinate to the metal or interact with the ligand by hydrogen bonding.

The complexes are unstable in moist air, in the presence of which they appear to decompose giving brown solids of indeterminate composition. The order of stability is $\mathrm{Li}>\mathrm{Na}>\mathrm{K}$.

From the table -6.2 , it is apparent that these complexes undergo transformation at a temperature higher than the melting point of the ligand, indicating thereby their greater thermal stability.

Table 6.2: Some physical properties of OHADNPz and its complexes

\begin{tabular}{|c|c|c|c|}
\hline Compound & Colour & $\begin{array}{l}\text { Melting Point / } \\
\text { decomposition ( }{ }^{\circ} \mathrm{c} \text { ) }\end{array}$ & Conductivity* \\
\hline OHADNPZ & Red & $250 \mathrm{~m}$ & - \\
\hline Liacac. OHADNPz & Cream colour & $280 \mathrm{~d}$ & 1.5 \\
\hline Naacac, OHADNPZ & Cream colour & $275 d$ & 2.0 \\
\hline Kacac, OHADNPZ & Cream colour & $265 d$ & 2.0 \\
\hline LiSalH. OHADNPZ & Grey colour & $268 d$ & 1.5 \\
\hline NaSalH. OHADNPz & Grey colour & $265 d$ & 2.5 \\
\hline KsalH, OHADNPZ & Grey colour & $260 \mathrm{~d}$ & 6.0 \\
\hline LiAnc, OHADNPZ & Brown colour & $274 d$ & 2.5 \\
\hline NaAnc. OHADNPZ & Brown colour & $272 \mathrm{~d}$ & 2.8 \\
\hline KAnc. OHADNPZ & Brown colour & $269 \mathrm{~d}$ & 4.5 \\
\hline LiPiCA. OHADNPz & Cream colour & $276 d$ & 2.0 \\
\hline NaPicA. OHADNPz & Cream colour & $270 d$ & 2.5 \\
\hline KPICA. OHADNPz & Cream colour & $268 d$ & 5.5 \\
\hline LiQinA. OHADNPz & Cream colout & $>300$ & 1.5 \\
\hline NaQinA OHADNPz & Cream colout & $>300$ & 2.5 \\
\hline KQinA. OHADNPz & Cream colout & $>300$ & 5.0 \\
\hline
\end{tabular}

- Motar Conductivity (ohm ${ }^{-1} \mathrm{~cm}^{2} \mathrm{~mol}^{-1}$ ) of $10^{3} \mathrm{M}$ solution in DMF.

\section{Infrared Spectra}

Infrared measurements for the ligands, their alkali metal salts and the complexes were made between $4000-650 \mathrm{~cm}^{-1}$ in Nujol mulls. Pertinent IR data for these compounds are shown in Table -6.3 .

The absorption bands of our principal interest in the IR spectra of O-hydroxyacetophenone - 2, 4 dinitrophenylhydrazone are 3360,3255,1605,1255 and 905 $\mathrm{cm}^{-1}$. The moderately strong bands at $3255 \mathrm{~cm}^{-1}$ in the spectra of the ligands may be attributed to stretching antisymmetric and symmetric - NH vibrations respectively . In the IR spectra of the complexes, these band exhibit a considerable downward. While the $\sim 3360 \mathrm{~cm}^{-1}$ band is observed at about $3200 \mathrm{~cm}^{-1}$, the vsymmetric $\mathrm{NH}$ band is observed at $3160 \mathrm{~cm}^{-1}$.
The $905 \mathrm{~cm}^{-1}$ band, most probably due to $v \mathrm{~N}-\mathrm{H}$ vibrations, is observed in the complexes as aplit bands at 945,940 and 870 $\mathrm{cm}^{-1}$ as in complexes of alkali metal salts of organic acids with O-Hydroxyacetophenone hydrazone and $\underline{\mathrm{O}}-$ Hydroxyacetophenone phenylhydrazone . The $605 \mathrm{~cm}^{-1}$ bands, most probably owing to $\mathrm{vC}=\mathrm{N}$ vibrations in the molecules of the ligand, has undergone a downward shift to an extent of $10-15 \mathrm{~cm}^{-1}$. These observations suggest that the coordination of ligands with alkali metals has taken place through the nitrogen atom of the hydrazone moiety.

The absorption band of $1255 \mathrm{~cm}^{-1}$ has been ascribed to the stretching $\mathrm{CO}$ (Phenolic) vibration in the ligand molecules. In the complexes, this band has undergone an upward shift to an extent of $1520 \mathrm{~cm}^{-1}$, indicating strong chelation owing to the intrinsicality of oxygen atom of the $-\mathrm{OH}$ group of the ligand.

In addition to these bands, a new broad band of weak to medium intensity in the region $2300-1950 \mathrm{~cm}^{-1}$ is observed in all the complexes. No such bands are observed in the spectra of either the alkali metal salts of the ligand or in the molecules of the ligand OHADNPz. This band could be assigned to $\mathrm{O}-\mathrm{H} \ldots . . \mathrm{O} / \mathrm{N} \ldots . . \mathrm{H}-\mathrm{O}$ absorption. This may be one of the dominant factors stabilising these complexes.

\section{Conductivities}

Molar conductivities were measured in DMF at $25^{\circ} \mathrm{c}$ at a concentration of $10^{-3} \mathrm{M}$. A value of $\sim 35-40 \mathrm{ohm}^{-1} \mathrm{Cm} 2$ mole $^{-1}$ appears characteristic of a 1:1 electrolyte ${ }^{16}$, whereas ideally moral conductivity of a neutral complex should be zero. From the result (Table 6.2), it is observed that molar conductivities of none of the complexes approach either ideal or 1:1 electrolyte. However, significantly low values of their molar conductivities suggest them to be non electrolytes.

\section{Probable Structure}

On the basis of element analyses, the general molecular formula of these complexes comes out to be ML.HL' where $\mathrm{M}=\mathrm{Li}, \mathrm{Na}$ or $\mathrm{K} ; \mathrm{L}=$ deprotonated $\mathrm{O}$ - nitrophenol,1 - nitroso - 2 - naphthol, 8 - Hydroxyquinoline, 2 - hydroxyl - 3 napthoic acid and Salicylic Acid; $\mathrm{HL}^{\prime}=\underline{\mathrm{O}}-$ hydroxyacetophenone $-2,4-$ dinitrophynyl hydrazone. The Infrared spectra of these complexes suggest the coordination

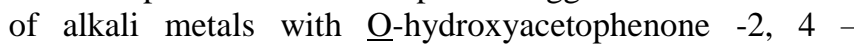
dinitrophynylhydrazone through oxygen atom of the hydroxyl group as well as the nitrogen atom of the hydrazone moiety. The infrared spectra of these complexes indicate the presence of hydrazone bonding in them. Keeping in view the fact that the six member chelate rings are most stable and that the ligand $\underline{\mathrm{O}}$-hydroxyacetophenone 2, 4 - dinitrophynylhydrazone behaves as a bidentate ligands. 


\section{International Journal of Science and Research (IJSR) ISSN (Online): 2319-7064 \\ Index Copernicus Value (2016): 79.57 | Impact Factor (2015): 6.391}

Table 6.3: I.R. Spectral data for the ligand OHADNPz and its alkali metal complexes

\begin{tabular}{|c|c|c|c|c|c|}
\hline \multirow[t]{2}{*}{ Compound } & \multicolumn{5}{|c|}{ Pertinent IR bands (in $\mathrm{cm}^{-1}$ ) } \\
\hline & Vasy NH & Vsym NH & $\operatorname{VC}-\mathrm{N}$ & $\begin{array}{c}\text { vco } \\
\text { (Phenolic) }\end{array}$ & $\mathrm{VN}=\mathrm{N}$ \\
\hline CHEDNPZ & 3360 & 3258 & 1605 : & $125 s$ & 906 \\
\hline Hees, OHADNPz & 3200 & 3160 & 1595 & 270 & $940,935,875$ \\
\hline Naxac: OHADNPZ & 3200 & 3160 & 1595 & 1270 & $945,900,870$ \\
\hline Kacac: OHADONP2 & 3200 & 3160 & 1590 & $12 \pi$ & $945,900,870$ \\
\hline LSall OHADNPz & 3205 & 3164 & 1595 & 1265 & $92,937,865$ \\
\hline NGSIL OHADNP2 & 3205 & 3163 & 1590 & 1270 & $945,940,870$ \\
\hline KeiHL OHAONP2 & 3205 & 3162 & 1590 & 1270 & $945,940,820$ \\
\hline LINC, OHADNP2 & 3200 & 3160 & 1590 & 1270 & $945,940,800$ \\
\hline NaAsc: OHADNPZ & 3200 & 3154 & 1590 & 1270 & $986,940,870$ \\
\hline Kase OHADNPX & 3200 & 3164 & $15 \% 0$ & 1270 & $945,940,870$ \\
\hline LiFich OWLANPZ & 3200 & 3467 & 1595 & 1265 & $945,940,890$ \\
\hline 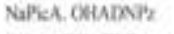 & 3205 & 3165 & 1593 & 1200 & $945,940,870$ \\
\hline KäicA. OHADNPZ & 3205 & 3160 & 1592 & 1220 & $945,940,870$ \\
\hline LOVinA OHADNR2 & 3205 & 3160 & 1590 & 1265 & $945,940,870$ \\
\hline $\mathrm{NaCint}$ OHADNP2 & \pm 210 & 3168 & 1590 & 1265 & $942,937,865$ \\
\hline SqinA. OriADNP2 & 3210 & 3157 & 1990 & 1265 & $942,937,855$ \\
\hline
\end{tabular}

The following structure may be suggested for these complexes.

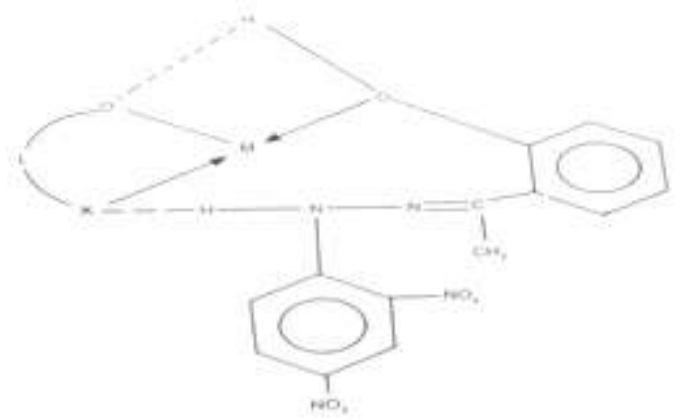

Figure 6.2

\section{Experimental}

Perparation of the Ligand O-Hydroxyacetophenone 2,4 dintrophenylhydrazone

The title ligand $\underline{\mathrm{O}-H y d r o x y a c e t o p h e n o n e ~ 2,4-\text { dintrophenyl }}$ hydrazone, was prepared as described by vishnoi. ${ }^{117}$

In a $250 \mathrm{ml}$ conical flask, $4 \mathrm{gm}$. of $2,4 \quad$ dintrophenylhydrazone was taken. $10 \mathrm{ml}$ absolute ethanol was added to it, following by $1 \mathrm{ml}$ conc. $\mathrm{H}_{2} \mathrm{SO}_{4}$. The contents were shaken and then heated to dissolve any solid. To, the warm solution, $10 \mathrm{ml} \mathrm{O}$-Hydroxyacetophenone was added. The contents were reshaken and cooled, when red crystalline solid O-Hydroxyacetophenone - $\quad 2,4 \quad-$ dintrophenylhydrazone appeared as crystals._The crystals were filtered, washed with cold water, recrystallized from alcohol and then dried in an electric over at $80^{\circ} \mathrm{c}$.

Its authenticity was established by elemental analyses and IR spectra. Red crystallized sample, obtained by us, has the melting point $250^{\circ} \mathrm{c}$.

Results of its elemental analyses are as follows:

Found: C, 53.25; H, 3.80: N, 17.58\%

$\mathrm{C}_{14} \mathrm{H}_{12} \mathrm{~N}_{4} \mathrm{O}_{5}$ requires: $\mathrm{C}, 53.16$; $\mathrm{H}, 3.79$ : $\mathrm{N}, 17.72 \%$
Adducts of O-Hydroxyacetophenone

2,4 dintrophenylhydrazone

1) Adducts with alkali metal salts of acetylacetone with 0 Hydroxyacetophenone - 2,4-dintrophenylhydrazone Alkali metal salt of acetylacetone with OHydroxyacetophenone - 2,4 - dintrophenylhydrazone were taken in a $30 \mathrm{ml}$ conical flask. About $30 \mathrm{ml}$ of absolute ethanol was added to it. The contents were refluxed on an electrically maintained hot plate, while constantly stirring the solution with the help of a magnetic stirrer. It was refluxed for about 6 hours. A clear solution was obtained. On cooling, coloured crystals came apart. It was filtered, washed with the solvent and then dried in an electric oven at $120^{\circ} \mathrm{c}$.

(a) Liacac.OHADNPz

Found: C, 53.84; H, 4.54; N, $13.27 \%$

$\mathrm{C}_{19} \mathrm{H}_{19} \mathrm{~N}_{4} \mathrm{O}_{7} \mathrm{Li}$ requires: $\mathrm{C}, 54.03 ; \mathrm{H}, 4.50 ; \mathrm{N}, 13.27 \%$

(b) Naacac. OHADNPz

Found : $\quad$ C, $52.24 ; \mathrm{H}, 4.30 ; \mathrm{N}, 12.70 ; \mathrm{Na}, 5.25 \%$

$\mathrm{C}_{19} \mathrm{H}_{19} \mathrm{~N}_{4} \mathrm{O}_{7} \mathrm{Na}$ requires: $\mathrm{C}, 52.05 ; \mathrm{H}, 4.34 ; \mathrm{N}, 12.78$;

$\mathrm{Na}, 5.25 \%$

(c) Kacac. OHADNPz
Found :
$\mathrm{C}, 50.37 ; \mathrm{H}, 4.12 ; \mathrm{N}, 12.25 ; \mathrm{K}, 8.50 \%$
$\mathrm{C}_{19} \mathrm{H}_{19} \mathrm{~N}_{4} \mathrm{O}_{7} \mathrm{~K}$ requires: $\mathrm{C}, 50.22 ; \mathrm{H}, 4.18 ; \mathrm{N}, 12.33$; $\mathrm{K}$, $8.59 \%$

2) Adducts with alkali metal salts of salicylaldehyde with $O$ Hydroxyacetophenone - 2,4-dintrophenylhydrazone

Alkali metal salt of salicylaldehyde and OHydroxyacetophenone - 2,4 - dintrophenylhydrazone were taken in a conical flask. About $30 \mathrm{ml}$ of absolute ethanol was added to it. The contents were refluxed on an electrically maintained hot plate, while constantly stirring the solution with the help of a magnetic stirrer. It was refluxed for about 6 hours. A clear solution was obtained. On cooling, coloured crystals came apart. It was filtered, washed with the solvent and then dried in an electric oven at $120^{\circ} \mathrm{c}$.

(a) $\underline{\mathrm{LiSalH} . \mathrm{OHADNPz}}$

Found : C, 56.95 ; H, 3.72; N, 12.24\%

$\mathrm{C}_{21} \mathrm{H}_{17} \mathrm{~N}_{4} \mathrm{O}_{7} \mathrm{Li}$ requires: $\mathrm{C}, 56.76 ; \mathrm{H}, 3.83 ; \mathrm{N}, 12.61 \%$

(b) $\mathrm{NaSalH.} \mathrm{OHADNPz}$

Found : C, $54.84 ; \mathrm{H}, 3.54 ; \mathrm{N}, 12.00 ; \mathrm{Na}, 5.0 \%$

$\mathrm{C}_{21} \mathrm{H}_{17} \mathrm{~N}_{4} \mathrm{O}_{7} \mathrm{Na}$ requires: $\mathrm{C}, 54.78 ; \mathrm{H}, 3.69 ; \mathrm{N}, 12.17$; Na, $5.0 \%$

(c) KSalH. OHADNPz

Found : C, $52.08 ; \mathrm{H}, 3.45 ; \mathrm{N}, 11.65 ; \mathrm{K}, 8.00 \%$

$\mathrm{C}_{21} \mathrm{H}_{17} \mathrm{~N}_{4} \mathrm{O}_{7} \mathrm{~K}$ requires : $\mathrm{C}, 52.94 ; \mathrm{H}, 3.57 ; \mathrm{N}, 11.76$; $\mathrm{K}, 8.19 \%$

3) Adducts with alkali metal salts of anthranilic acid with 0 Hydroxyacetophenone - 2,4-dintrophenylhydrazone

Equimolar proportions of alkali metal anthranilate and $\mathrm{O}$ Hydroxyacetophenone - 2,4 - dintrophenylhydrazone were taken in a $150 \mathrm{ml}$ conical flask. About $30 \mathrm{ml}$ of absolute ethanol was added to it. The contents were refluxed on an electrically maintained hot plate, while constantly stirring the solution with the help of a magnetic stirrer. It was refluxed for about 6 hours. A clear solution was obtained. On cooling, coloured crystals came apart. It was filtered,

Volume 6 Issue 12, December 2017 


\section{International Journal of Science and Research (IJSR) \\ ISSN (Online): 2319-7064}

Index Copernicus Value (2016): 79.57 | Impact Factor (2015): 6.391

washed with the solvent and then dried in an electric oven at $120^{\circ} \mathrm{c}$.

(a) LiAnc.OHADNPz

Found : C, $54.95 ; \mathrm{H}, 3.85 ; \mathrm{N}, 15.20 \%$

$\mathrm{C}_{21} \mathrm{H}_{18} \mathrm{~N}_{5} \mathrm{O}_{7} \mathrm{Li}$ requires: $\mathrm{C}, 54.90 ; \mathrm{H}, 3.92 ; \mathrm{N}, 15.25 \%$

(b) NaAnc. OHADNPz

Found : C, $53.15 ; \mathrm{H}, 3.82 ; \mathrm{N}, 14.80 ; \mathrm{Na}, 4.50 \%$

$\mathrm{C}_{21} \mathrm{H}_{18} \mathrm{~N}_{5} \mathrm{O}_{7} \mathrm{Na}$ requires: $\mathrm{C}, 53.05 ; \mathrm{H}, 3.79 ; \mathrm{N}, 14.74$; $\mathrm{Na}, 4.84 \%$

(c) KAnc. OHADNPz

Found : C, 51.37 ; H, 3.72; N, 14.30; K, 7.85\%

$\mathrm{C}_{21} \mathrm{H}_{18} \mathrm{~N}_{5} \mathrm{O}_{7} \mathrm{~K}$ requires: $\mathrm{C}, 51.32 ; \mathrm{H}, 3.66 ; \mathrm{N}, 14.26$;

$\mathrm{K}, 7.94 \%$

4) Adducts of alkali metal salts of picolinic acid with 0 Hydroxyacetophenone - 2,4-dintrophenylhydrazone Alkali metal salt of picolinic acid and the ligand OHydroxyacetophenone - 2,4 - dintrophenylhydrazone were taken in a conical flask. About $30 \mathrm{ml}$ of absolute ethanol was added to it. The contents were refluxed. A clear solution was obtained. It was refluxed for about 6 hours. It was concentrated and cooled, when coloured crystals came apart. It was filtered, washed with the solvent and then dried in an electric oven at $120^{\circ} \mathrm{c}$.

(a) LiPicA.OHADNPz

Found : C, $53.98 ; \mathrm{H}, 3.65 ; \mathrm{N}, 15.78 \%$

$\mathrm{C}_{20} \mathrm{H}_{16} \mathrm{~N}_{5} \mathrm{O}_{7} \mathrm{Li}$ requires : $\mathrm{C}, 53.98 ; \mathrm{H}, 3.59 ; \mathrm{N}, 15.73 \%$

(b) NaPicA. OHADNPz

Found : C, $52.11 ; \mathrm{H}, 3.52 ; \mathrm{N}, 15.23$; Na, 5.00\%

$\mathrm{C}_{20} \mathrm{H}_{16} \mathrm{~N}_{5} \mathrm{O}_{7} \mathrm{Na}$ requires: $\mathrm{C}, 52.06 ; \mathrm{H}, 3.47 ; \mathrm{N}, 15.18 ; \mathrm{Na}$, $4.99 \%$

(c) KPicA. OHADNPz

Found : C, $50.36 ; \mathrm{H}, 3.40 ; \mathrm{N}, 14.70 ; \mathrm{K}, 8.25 \%$

$\mathrm{C}_{20} \mathrm{H}_{16} \mathrm{~N}_{5} \mathrm{O}_{7} \mathrm{~K}$ requires: $\mathrm{C}, 50.31 ; \mathrm{H}, 3.35 ; \mathrm{N}, 14.67$; $\mathrm{K}, 8.18 \%$

5) Adducts with alkali metal salts of Quinaldinic acid with OHydroxyacetophenone - 2,4-dintrophenylhydrazone Equimolar proportions of alkali metal salt of quinaldinic acid and O-Hydroxyacetophenone - 2,4 dintrophenylhydrazone were taken in a $150 \mathrm{ml}$ conical flask. About $30 \mathrm{ml}$ of absolute ethanol was added to it. The contents were refluxed on an electrically maintained hot plate, while constantly stirring the solution with the help of a magnetic stirrer. It was refluxed for about 6 hours. A clear solution was obtained. It was concentrated and then cooled, when the adduct came apart. It was filtered, washed with the solvent and then dried in an electric oven at $120^{\circ} \mathrm{c}$.

(a) LiQuinA.OHADNPz

Found: C, 58.23 ; H, 3.69; N, 14.09\%

$\mathrm{C}_{24} \mathrm{H}_{18} \mathrm{~N}_{5} \mathrm{O}_{7} \mathrm{Li}$ requires: $\mathrm{C}, 58.18 ; \mathrm{H}, 3.64 ; \mathrm{N}, 14.14 \%$

(b) NaQuinA. OHADNPz

Found : C, $56.40 ; \mathrm{H}, 3.57 ; \mathrm{N}, 13.62 ; \mathrm{Na}, 4.45 \%$

$\mathrm{C}_{24} \mathrm{H}_{18} \mathrm{~N}_{5} \mathrm{O}_{7} \mathrm{Na}$ requires: $\mathrm{C}, 56.36 ; \mathrm{H}, 3.52 ; \mathrm{N}, 13.69$;

$\mathrm{Na}, 4.50 \%$

(c) KQuinA. OHADNPz

Found: C, $54.70 ; \mathrm{H}, 3.45 ; \mathrm{N}, 13.23 ; \mathrm{K}, 7.35 \%$
$\mathrm{C}_{24} \mathrm{H}_{18} \mathrm{~N}_{5} \mathrm{O}_{7} \mathrm{~K}$ requires : C, $54.65 ; \mathrm{H}, 3.41 ; \mathrm{N}, 13.28$;

$\mathrm{K}, 7.40 \%$

\section{References}

[1] N.V. Sidgwick and F.M. Brewer : J. Chem. Soc., 1925, 127, 2379

[2] F.M. Brewer : J. Chem. Soc., 1931, 361

[3] C.L. Brady and M.D. Porter : J. Chem. Soc., 1933, 840

[4] A.K. Banerjee, A.J. Layton, R.S. Nyholm : Nature, 1968, 217, 1147

[5] A.K. Banerjee, A.J. Layton, R.S. Nyholm and M.R. Truter : J. Chem Soc (A), 1969, 2536

[6] A.J.K. Kolombos : Ph. D. Thesis, University of London, 1970

[7] M.A. Bush, H. Luth and M.R. Truter : J. Chem. Soc. (A), 1971, 740

[8] A.K. Banrjee, D. Prakash and S.K. Roy : J. Indian Chem. Soc., 1979, 53, 773

[9] D.L. Hughes and M.R. Truter : J. Chem, Soc. (Dalton), 1979, 1520

[10] D. Prakash and S.P. Singh : J. Indian Chem. Soc., 1981, 58, 1143

[11]D. Prakash and S.P. Singh : Polyhedron, 1984, 3, 243

[12]D. Prakash and S.P. Singh : J. Indian Chem. Soc. 1987, 64,52

Volume 6 Issue 12, December 2017

www.ijsr.net

Licensed Under Creative Commons Attribution CC BY 